\title{
Identification of New Lithic Clasts in Lunar Breccia 14305 by micro-CT and micro-XRF analysis
}

\author{
Ryan A. Zeigler ${ }^{1}$, Paul K. Carpenter ${ }^{2}$ and Bradley L. Jolliff ${ }^{2}$ \\ 1. NASA - JSC, Mail Code KT, 2101 NASA parkway, Houston, TX, 77058. ryan.a.zeigler@nasa.gov \\ 2. Washington University in St. Louis, CB 1169, 1 Brookings Dr., St. Louis, MO, 63110.
}

From 1969 to 1972, Apollo astronauts collected $382 \mathrm{~kg}$ of rocks, soils, and core samples from six locations on the surface of the Moon. The samples were initially characterized, largely by binocular examination, in a custom-built facility at Johnson Space Center (JSC), and the samples have been curated at JSC ever since. Despite over 40 years of study, demand for samples remains high $(\sim 500$ subsamples per year are allocated to scientists around the world), particularly for plutonic (e.g., anorthosites, norites, etc.) and evolved (e.g., granites, KREEP basalts) lithologies. The reason for the prolonged interest is that as new scientists and new techniques examine the samples, our understanding of how the Moon, Earth, and other inner Solar System bodies formed and evolved continues to grow. Scientists continually clamor for new samples to test their emerging hypotheses. Although all of the large Apollo samples that are igneous rocks have been classified, many Apollo samples are complex polymict breccias that have previously yielded large (cm-sized) igneous clasts. In this work we present the initial efforts to use the non-destructive techniques of micro-computed tomography (micro-CT) and micro x-ray fluorescence (micro-XRF) to identify large lithic clasts in Apollo 14 polymict breccia sample 14305.

The sample in this study is 14305,483 , a $150 \mathrm{~g}$ slab of regolith breccia 14305 measuring $10 \times 6 \times 2 \mathrm{~cm}$ (Figure 1a). The sample was scanned at the University of Texas High-Resolution X-ray CT Facility on an Xradia MicroXCT scanner. Two adjacent overlapping volumes were acquired at $49.2 \mu \mathrm{m}$ resolution and stitched together, resulting in 1766 slices. Each volume was acquired at $100 \mathrm{kV}$ accelerating voltage and $98 \mathrm{~mA}$ beam current with a $1 \mathrm{~mm} \mathrm{CaF} 2$ filter, with 2161 views gathered over $360^{\circ}$ at 3 seconds acquisition time per view. Micro-XRF analyses were done at Washington University in St. Louis, Missouri on an EDAX Orbis PC micro-XRF instrument. Multiple scans were made at $40 \mathrm{kV}$ accelerating voltage, $800 \mathrm{~mA}$ beam current, $30 \mu \mathrm{m}$ beam diameter, and a beam spacing of 30-120 $\mu \mathrm{m}$.

The micro-CT scan of 14305,483 (Figure 2) was able to identify several large lithic clasts $(\sim 1 \mathrm{~cm})$ within the interior of the slab. These clasts will be exposed by band-sawing or chipping of the slab, and their composition more fully characterized by subsequent micro-XRF analysis. In addition to lithic clasts, the micro-CT scans identified numerous mineral clasts, including many FeNi metal grains, as well as the prominent fractures within the slab.

The micro-XRF analyses (Figure 1b,c) of the slab surfaces revealed the bulk chemical compositions (qualitative) of the different clast types observed. In particular, by looking at the ratios of major elements (e.g. Ca:Mg:Fe), differences among the many observed clast types are readily observed. Moreover, several clasts not apparent to the naked eye were revealed in the K:Al:Si ratio map. The scans are also able to identify small grains of Zr- and P-rich minerals (not shown), which could in turn yield important age dates for the samples. 
These initial scans illustrate the usefulness of micro-CT and micro-XRF analyses on pristine lunar samples in order to identify new clast materials in polymict lunar breccias. Comparison to previous work on the same samples should allow us to confidently identify most clast lithologies observed.
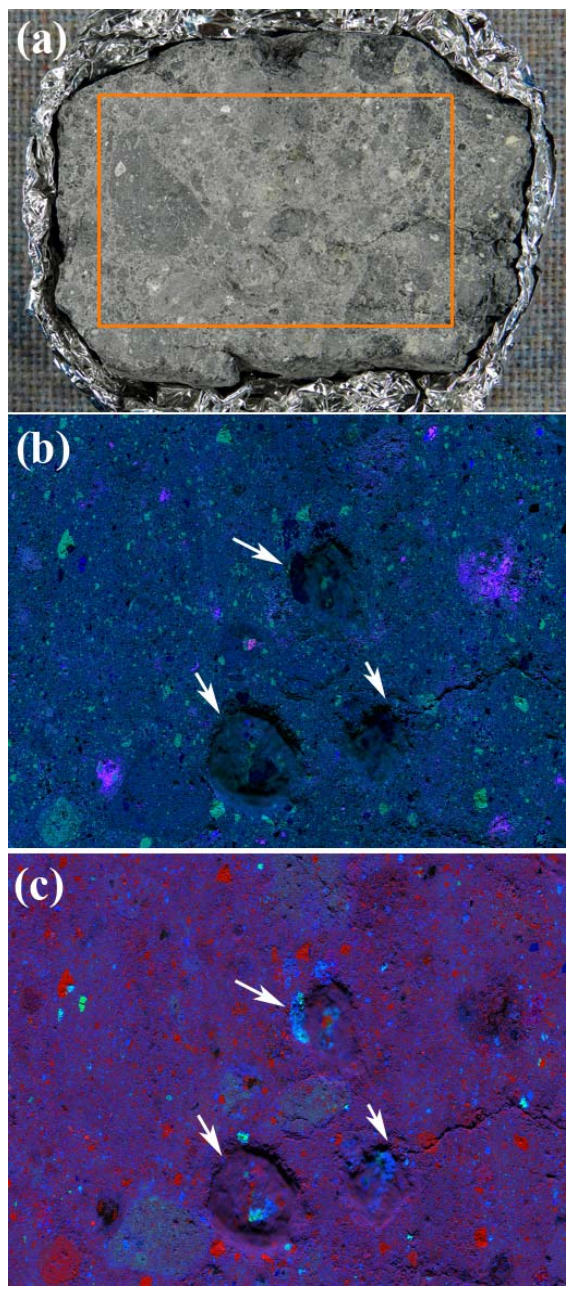

Figure 1 (left): (a) Macroscopic image of 14305,483 slab. Area in parts $\mathrm{b}+\mathrm{c}$ outlined in orange. Field of view is $10 \mathrm{~cm}$ wide. (b) X-ray $\mathrm{RGB}$ composite image of the surface of 14305,483. $\mathrm{K}=$ red, $\mathrm{Al}=$ green, $\mathrm{Si}=$ blue. White arrows denote pits in the sample. (c) Xray RGB composite image of the surface of 14305,483 . Ca $=$ red, $\mathrm{Mg}=$ green, $\mathrm{Fe}=$ blue .

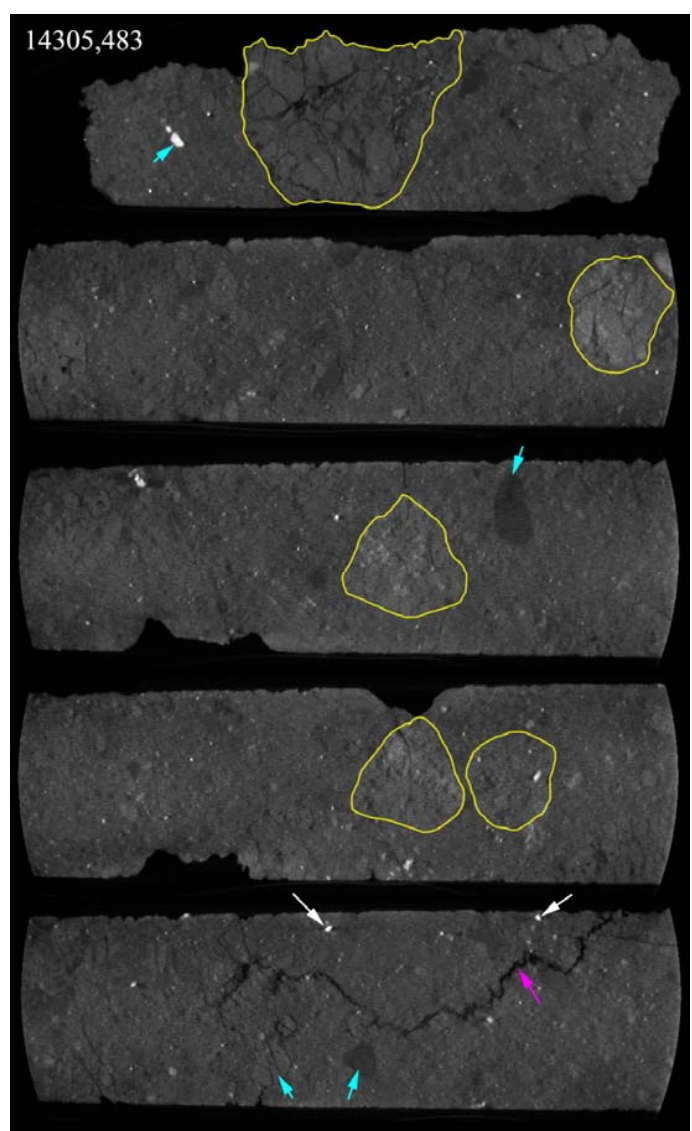

Figure 2 (right). Montage of 5 different micro-CT slices through 14305,483 . Prominent lithic clasts are outlined in yellow for ease of viewing. Significant mineral clasts are denoted by cyan arrows. White

arrows denote FeNi metal clasts. The magenta arrow denotes a major fracture. Field of view is $5 \mathrm{~cm}$. 